\title{
Johne's Disease Vaccines Past, Present and Future
}

\author{
Shanmugasundaram Karuppusamy and Bhupendra Nath Tripathi* \\ Department of Veterinary, National Centre for Veterinary Type Cultures-National Research Centre on Equines, India
}

Submission: August 13, 2018; Published: September 12, 2018

*Corresponding author: Bhupendra Nath Tripathi, Department of Veterinary, National Centre for Veterinary Type Cultures-National Research Centre on Equines, Hisar-125001, Haryana, India, Tel: +91-1662275787; Email: bntripathi1@yahoo.co.in

\begin{abstract}
Control and eradication of Johne's disease of ruminants caused by Mycobacterium avium sub sp paratuberculosis (MAP) still remains a formidable challenge before the scientific community because of insidious nature of the infection and our inability to diagnose subclinical cases. Vaccination against MAP is considered an alternate option to control JD. Inactivated vaccines, live attenuated vaccines, subunit vaccines, DNA vaccines and recombinant protein-based vaccines have been developed for JD with variable successes. In this mini review, we have discussed various types of vaccines developed of JD and their current status. Searching of new vaccines and testing against MAP infection is still a very practical approach to control and eradicate the JD.
\end{abstract}

\section{Introduction}

Johne's Disease (JD) or paratuberculosis is an incurable, chronic granulomatous enteritis of ruminants and other animals and is caused by Mycobacterium avium subsp paratuberculosis (MAP) [1]. The organism has also been implicated with Crohn's disease of humans. JD incurs huge economic losses to the dairy and small ruminant industry worldwide. During early stages of the infection, infected animals' sheds MAP intermittently in the feces and thus acts as a source of infection to the susceptible animals [2]. Lack of proper diagnostic assays in identification of the subclinical cases of MAP infection is a major challenge in the control and eradication of the disease [3]. Alternatively, vaccination against MAP is a viable option to control and reduce the economic burden due to JD [3]. In this mini review, we have discussed the recent development about vaccination against MAP infection and futurology.

Vaccination trial against MAP infection was initiated in 1990 with whole cell antigens obtained from heat killed MAP organisms and was suspended in oil adjutants [4]. Inactivated whole MAP cells have been used to prepare commercial vaccines such as Mycopar, Gudair and Silirum. Mycopar was developed from MAP strain 18 (now identified as M avium subsp avium), whereas Gudair and Silirum from MAP F316 strain [5]. These vaccines have been shown to minimize MAP shedding and disease transmission but do not protect the animals from new infections [6].

Sequence analysis and annotation of MAP genomes, prediction of proteins (structure, sub-cellular locations and antigenicity) based on the bioinformatics analysis and subsequent validation with laboratory experiments opened up a new era in the development of vaccines against MAP [6,7]. A rational frame model has been proposed recently to test the new generation vaccine against MAP. It consists of three phases such as phase I (screening of candidates in bovine macrophages), phase II (mouse challenge models) and phase III (goat challenge model) to develop MAP vaccines [8].

\section{Vaccine types}

Presently Live Attenuated Vaccines (LAV), subunit vaccines, DNA vaccines and recombinant protein-based vaccines are available for the JD with variable success reports. Several mutants of MAP have been produced by allelic exchange, phage-mediated and transposon mutagenesis to attenuate the MAP virulence [3]. Recently, transposon mutant bank was constructed to 13,536 MAP K-10 Tn5367 and some of the mutants like 4H2, 30H9, 22F4 and 40A9 showed reduced virulence with Bovine macrophages and Monocyte-derived macrophages cells [9]. However, further studies are warranted to assess their suitability as LAV candidates. Mutants generated by direct allelic exchange methods targeting known virulence genes such as pknG, relA, ppiA, mpt64, lsr2, leuD, sigL, sigH and secA2 $[3,10,11]$ were screened as LAV and the results showed that $\Delta$ relA, $\Delta$ ppiA, $\Delta$ leuD, $\Delta$ mpt64, $\Delta$ secA2 $\Delta$ sigL and $\Delta$ sigH had protective immune response against MAP infection in the experimental models tested. LAV stimulates both innate and adaptive immune response that is considered an advantage with these vaccines. However, it would not differentiate between infected and the vaccinated animals [6].

Subunit vaccines using MAP DNA or recombinant protein antigens have also been tested. These vaccines may overcome the interference in the diagnosis of bovine tuberculosis in comparison to the whole MAP cell-based vaccines (killed or attenuated) [3]. Different antigens like antigen 85 Complex (A, 
B and C), LprG, MAP1518, MAP0261c, MAP2698c, MAP3567, MAP3184, SodD, AhpC, AhpD and Hsp70 were tested as subunit vaccines. These studies were mainly focused on the protective immune responses due to cell mediated immune responses rather than humoral immune responses [3]. However, it has been shown that a protective response from $\mathrm{Hsp} 70$ was due to activation of B lymphocytes. Unfortunately, none of subunit vaccine candidates tested so far could able to provide complete protection in the murine, calf and goat models [8].

Delivery of expressed MAP antigens through attenuated strains like Salmonella and Lactobacillus salivarius was shown to be an alternate way to stimulate protective mucosal immune responses [12,13]. This approach is, however in primitive stage and needs further studies to prove its usefulness in the development of subunit vaccines. Combination of viral vectors with MAP antigens was also tried to develop DNA subunit vaccines. AhpC, gsd, p12 and mpa gene fusion constructs were developed with viral vectors and used to test their immune protective role against MAP. Results showed protection against subsequent challenges studies in murine models [14]. In another study in which MAP antigens were delivered through nonreplicative human adenovirus 5 and modified vaccinia virus Ankara recombinant, induced MAP specific CD4+ and CD8+ immune responses and protected from the MAP infection [15].

\section{Conclusions and future directions}

Diverse strategies have been used to develop vaccines against MAP. Unfortunately, as of now none of the live attenuated or subunit vaccines are available commercially. The most important areas to focus are

i) MAP cell biogenesis to understand the biology of MAP,

ii) host-pathogen interactions to know about how bacteria overcome highly orchestrated host defence mechanisms such as innate and adaptive immunity,

iii) pathogenomic analysis of MAP strains to know geographical distribution and SNPs to select an appropriate MAP strain for further studies,

iv) top down proteomic approaches to identify more MAPspecific antigens and their iso-forms for further screening,

v) studies on post translational modification of MAP proteins to understand the pathobiology and immunogenicity and thus will offer to select new level MAP-specific epitoes as a better vaccine candidate and

vi) long term trials that mimic with natural MAP infection. Even though, as of now none of the vaccines gives complete protection against MAP but searching of new vaccines and testing against MAP infection is still a very practical approach to control and eradicate the JD.

\section{References}

1. Walsby A E (1972) "Structure and function of gas vacuoles." Bacterial Rev 36(1): 1-32.

2. WalsbyA E (1994)"Gas vesicles." Microbiological rev 58 (1): 94-144.

3. Oren A (2013) The Function of Gas Vesicles in Halophilic Archaea and Bacteria: Theories and Experimental Evidence. Life (Basel) 3(1): 1-20.

4. Pfeifer F (2012) Distribution, formation and regulation of gas vesicles. Nat Rev Microbiol 10(10): 705-715.

5. Cai L, Zhao D, Hou J, Wu J, Cai S (2012) Cellular and organellar membrane-associated proteins in haloarchaea: Perspectives on the physiological significance and biotechnological applications. Sci China Life Sci 55(5): 404-414.

6. Offner S, Ziese U, Wanner G, Typke D, Pfeifer F (1998) Structural characteristics of halobacterial gas vesicles. Microbiology, 144(5): 13311342.

7. Daviso E, Belenky M, Griffin RG, Herzfeld J (2013) Gas Vesicles across Kingdoms: A Comparative Solid-State Nuclear Magnetic Resonance Study.J Mol Microbiol Biotechnol 23(4-5): 281-289.

8. Csiszàr K, Houmard J, Damerval T, Tandeau de Marsac N (1987) Transcriptional analysis of the cyanobacterial gvpABC operon in differentiated cells: occurrence of an antisense RNA complementary to three overlapping transcripts. Gene 60(1): 29-37.

9. Krüger K, Pfeifer F (1996) "Transcript analysis of the c-vac region and differential synthesis of the two regulatory gas vesicle proteins GvpD and GvpE in Halobacterium salinarium PHH4". J Bacteriol 178 (14): 4012-4019.

10. Tashiro Y, Monson R, Ramsay J, Salmond G (2016) Molecular genetic and physical analysis of gas vesicles in buoyant enterobacteria. Environ Microbiol 18(4): 1264-1276.

11. Pfeifer F (2012) Distribution, formation and regulation of gas vesicles. Nature Reviews Microbiology 10(10): 705-715.

12. DasSarma S, DasSarma P (2015) “Gas vesicle nanoparticles for antigen display." Vaccines (Basel) 3(3): 686-702.

13. Andar AU, Karan R, Pecher WT, DasSarma P, Hedrich WD, et al. (2017) Microneedle-Assisted Skin Permeation by Nontoxic Bioengineerable Gas Vesicle Nanoparticles. Mol Pharm 14(3): 953-958.

14. Das Sarma P, Negi V, Balakrishnan A, Kim J, Karan R, et al. (2015) Haloarchaeal Gas Vesicle Nanoparticles Displaying Salmonella Antigens as a Novel Approach to Vaccine Development. Procedia in Vaccinology 9: 16-23.

15. Balakrishnan A, DasSarma P, Bhattacharjee O, Kim J, DasSarma S, et al. (2016) Halobacterial nano vesicles displaying murine bactericidal permeability-increasing protein rescue mice from lethal endotoxic shock. Scientific Reports 6(1).

16. Sundararajan A, Lu-Kwang Ju (2006) "Use of cyanobacterial gas vesicles as oxygen carriers in cell culture." Cytotechnology 52(2): 139-149.

17. Lakshmanan A, Farhadi A, Nety SP, Lee-Gosselin A, Bourdeau RW, et al. (2016) Molecular Engineering of Acoustic Protein Nanostructures. ACS Nano 10(8): 7314-7322. 
Advances in Biotechnology \& Microbiology

-This work is licensed under Creative

Commons Attribution 4.0 Licens

DOI: 10.19080/AIBM.2018.11.555807
Your next submission with Juniper Publishers will reach you the below assets

- Quality Editorial service

- Swift Peer Review

- Reprints availability

- E-prints Service

- Manuscript Podcast for convenient understanding

- Global attainment for your research

- Manuscript accessibility in different formats ( Pdf, E-pub, Full Text, Audio)

- Unceasing customer service

Track the below URL for one-step submission https://juniperpublishers.com/online-submission.php 